\title{
Justicia social: accesibilidad a espacios públicos en contextos de marginación urbana en Ciudad Juárez, Chihuahua, México
}

Recepción: 16 de octubre de 2020 - Evaluación: 4 de noviembre de 2020 - Aprobación: 8 de noviembre de 2021

Resumen: El espacio público va más allá de una unidad territorial que forma parte del equipamiento, ya que este tipo de áreas pueden contribuir significativamente y de muchas maneras al mejoramiento de la calidad de vida y es por ello por lo que una distribución justa de este tipo de espacios tendría que ser equitativa y accesible para todas las personas. Por ello, se plantea como objetivo de este trabajo analizar la accesibilidad a espacios públicos en contextos de marginación desde el enfoque de justicia social en una ciudad fronteriza del norte de México, en Ciudad Juárez, Chihuahua. En la metodología empleada se utilizó como herramienta principal el análisis espacial a través del cual se georreferenciaron y caracterizaron los espacios públicos para evaluar la accesibilidad de la población a estos sitios y también se hizo una caracterización de la marginación en la ciudad de estudio para posteriormente relacionar ambas variables. Entre los resultados obtenidos, destaca la distribución desigual de accesibilidad a las áreas públicas, su fragmentación y atomización, así como la falta de equipamiento y cuidado, por lo que entre las conclusiones se observa que, aunque aparentemente hay una gran cantidad de espacios públicos en Ciudad Juárez, esto no se traduce en un indicador elevado de accesibilidad justa a estos espacios y, de hecho, la accesibilidad de la población con niveles de marginación altos es muy limitada a sitios públicos con buena calidad.

Palabras clave: accesibilidad, espacio público, justicia social, marginación.

Para citar: Romo Aguilar, M. de L., \& Maldonado, J. D. (2022). Justicia social: accesibilidad a espacios públicos en contextos de marginación urbana en Ciudad Juárez, Chihuahua, México. Perspectiva Geográfica, 27(1), 11-31. https://doi.org/10.19053/01233769.11922

En este artículo se presentan algunos de los resultados del proyecto "Espacios públicos y actividad física en ciudades del norte de México" (EPAF) (PDCPN 2015-482), financiado por el Consejo Nacional de Ciencia y Tecnología (Conacyt). Responsables del proyecto: Ietza Bojórquez, El Colegio de la Frontera Norte (El Colef) y María de Lourdes Romo A. (El Colef). e investigadora, El Colegio de la Frontera Norte (El Colef), Departamento de Estudios Urbanos y del Medio Ambiente (DEuma), Sede Juárez, Chihuahua. Correo: 1romo@colef.mx. Orcid: http://orcid.org/0000-0001-6380-2770 


\title{
Social justice: accessibility to public spaces in contexts of urban exclusion in Ciudad Juárez, Chihuahua, Mexico
}

Summary: Public space goes beyond a territorial unit that is part of the infrastructure since
this type of area can contribute significantly and in many ways to the improvement of the
quality of life, which is why a fair distribution of this type of space should be equitable and
accessible to everyone. That is why the objective of this study is to analyze the accessibility of
public spaces in contexts of exclusion from the perspective of social justice in a border city in
the north of Mexico, in Ciudad Juárez, Chihuahua. The main tool used in the methodology is
spatial analysis, through which public spaces were geo-referenced and categorized to evaluate
the accessibility of the population to these sites, and a classification of social exclusion in the city
under study was also carried out to later relate the two variables. Among the results obtained,
the unequal distribution of access to public areas, their fragmentation and atomization, the
lack of equipment and maintenance of these public spaces stand out, and the conclusions are
that, although there is apparently a large number of public spaces in Ciudad Juárez, this does
not translate into a high indicator of fair access to these spaces and, in fact, the accessibility of
the population with high levels of social exclusion is very limited to good quality public places.

Keywords: accessibility, public space, social justice, social exclusion.

\section{Justiça social: acessibilidade a espaços públicos em contextos de marginalização urbana na Cidade Juárez, Chihuahua, México}

\begin{abstract}
Resumo: O espaço público vai além de uma unidade territorial que faz parte do equipamento, já que este tipo de áreas podem contribuir significativamente e de muitas maneiras para a melhoria da qualidade de vida e é por isso que uma distribuição justa deste tipo de espaços teria que ser equitativa e acessível para todas as pessoas. Por isso, propõe-se como objetivo deste trabalho analisar a acessibilidade a espaços públicos em contextos de marginalização desde o enfoque de justiça social em uma cidade fronteiriça do norte do México, em Cidade Juárez, Chiuaua. Na metodologia utilizada utilizou-se como ferramenta principal a análise espacial através do qual se georreferenciaram e caracterizaram os espaços públicos para avaliar a acessibilidade da população a estes sítios e também se fez uma caracterização da marginalização na cidade de estudo para mais tarde relacionar as duas variáveis. Entre os resultados obtidos, destaca-se a distribuição desigual de acessibilidade às áreas públicas, a sua fragmentação e atomização, bem como a falta de equipamento e cuidado, pelo que entre as conclusões observa-se que, embora aparentemente exista uma grande quantidade de espaços públicos em Cidade Juárez, isto não se traduz num indicador elevado de acessibilidade justa a estes espaços e, de fato, a acessibilidade da população com níveis de marginalização elevados é muito limitada a sítios públicos de boa qualidade.
\end{abstract}

Palavras-chave: acessibilidade, espaço público, justiça social, marginalização. 


\section{Introducción}

Las áreas urbanas de carácter público se han convertido en sitios de significación individual y colectiva, en escenarios de lo político, de esparcimiento y recreo, donde las posibilidades de ocio, deportes, desplazamiento y vida comunitaria adquieren sentido (Cardona, 2008). Tradicionalmente los espacios públicos se entienden como parte del dominio público que mantiene un uso colectivo por ser accesibles y ser utilizados de múltiples formas, además de facilitar los contactos sociales y favorecer la creación de identidad social (De la Torre, 2015). El espacio público es el escenario ideal para el desarrollo de la sociedad, ya que es donde se producen todo tipo de interacciones y su amplio significado hace referencia a la inclusión, a la diferencia, al encuentro, a deambular y a una zona que garantiza tanto la salud pública como la privada (Restrepo, 2016).

Para Franco y Zabala (2012), la ciudad contemporánea debe incorporar de manera integral y equitativa lo ambiental, lo económico y lo social para todos los ciudadanos, a través de prácticas que garanticen el acceso igualitario al espacio público, a recursos de movilidad y, en general, a los diferentes equipamientos, mientras que Duhau y Giglia (2004) consideran que buena parte de los conflictos por el espacio pueden ser apreciados al mismo tiempo como el producto de los efectos espaciales de determinado tipo de contexto urbano.

Sin embargo, la ciudad contemporánea ha quedado con zonas en completo rezago en cuanto a equipamiento urbano se refiere, lo cual afecta el desempeño de las actividades cotidianas de los ciudadanos y su desarrollo humano (Herrera, 2017). No es fácil comprender las características de la unidad territorial, sus transformaciones y los grandes desafíos que se desarrollan en el campo y la ciudad, ya que estos procesos tienen en común un aumento de pobreza y de precariedad de los equipamientos en infraestructura urbana, además del acelerado crecimiento del proceso de urbanización, lo que hace pensar en cómo y quién construye la ciudad, si se toma la mejor decisión de planificación y si se identifican los grandes problemas que afectan a quien habita el territorio (Ocampo, 2013).

En las ciudades latinoamericanas, el espacio público está siendo actualmente objeto de gestión con el fin de contribuir al mejoramiento de la calidad de vida de sus habitantes a partir de la creación de nuevos lugares públicos y la recuperación de sitios abandonados, dada la importancia que se le viene dando para el sostenimiento de distintas prácticas sociales, entre las que se pueden destacar el comercio, la protesta ciudadana, el arte, la lúdica y el entretenimiento, el deporte, la religiosidad y las expresiones de los distintos movimientos sociales (Páramo et al., 2016). De acuerdo con la relevancia y los beneficios del lugar público, este tipo de sitio supondría una distribución equitativa en contextos urbanos y con esto en mente se planteó como objetivo analizar la accesibilidad a espacios públicos en contextos de marginación desde el enfoque de justicia social en una ciudad de la frontera norte de México, tomando como caso de estudio Ciudad Juárez, Chihuahua.

El enfoque de justicia social está estrechamente relacionado con la pobreza y con la marginación, que generalmente se han vinculado con la dificultad de acceder a suelo barato donde producir una vivienda digna, a infraestructura básica (agua y drenaje) y a equipamiento comunitario como centros de salud, guarderías, escuelas y áreas deportivas y culturales. Este asunto también se ha analizado en relación con las condiciones de desigualdad socioeconómica y urbana, que permiten ubicar a los individuos, los colectivos sociales y los barrios o zonas de una ciudad en la escala de distribución de bienes, recursos y servicios en los que se localizan en el territorio (Mier y Terán et al., 2012). Este artículo aporta específicamente al análisis de la relación entre accesibilidad a espacios públicos y marginación urbana desde un enfoque de justicia social. 
La concentración de la población provoca desequilibrios sociales y territoriales, entre los que se destacan problemas de marginalidad, desigualdad y desequilibrios regionales (Dávila et al., 2016), mientras que la implementación de políticas a partir de programas de embellecimiento de la imagen urbana demuestra que este tipo de intervenciones constituyen una forma de legitimación y control social que no hace más que aumentar la fragmentación social (Filipe, 2017). El crecimiento de la ciudad actual está caracterizado en parte por la segregación y por la segmentación urbana, en donde el espacio público es el lugar en el cual se evidencian con mayor fuerza los problemas de desigualdad e inseguridad social y los sectores marginados son los más vulnerables a esta condición (Guzmán et al., 2015).

México es un país donde aún existen acentuados problemas socioeconómicos como la pobreza, la marginación y una marcada desigualdad en la distribución del ingreso. La pobreza implica falta o insuficientes ingresos para la supervivencia humana o familiar, mientras que la marginación hace referencia a una exclusión de ciertos grupos sociales de beneficios que puedan propiciar mejores condiciones de vida (García et al., 2012).

El área de estudio se localiza en la frontera norte del estado de Chihuahua (México) y colinda con la ciudad de El Paso, Texas (Estados Unidos) (Figura 1). Se ve delimitada al norte y noreste por el río Bravo, además de una sierra montañosa al poniente y una extensión desértica de arenales hacia el sur. La mancha urbana ocupaba hasta el año 2016 una superficie de 32.119,57 hectáreas, con una población de 1.391.180 habitantes y una densidad de ocupación de 41,82 hab./ha, además de presentar un proceso de crecimiento urbano donde existen baldíos y zonas residenciales desconectadas del centro de la ciudad, lo que habla de un crecimiento disperso y desorganizado (Instituto Municipal de Investigación y Planeación [IMIP], 2016).

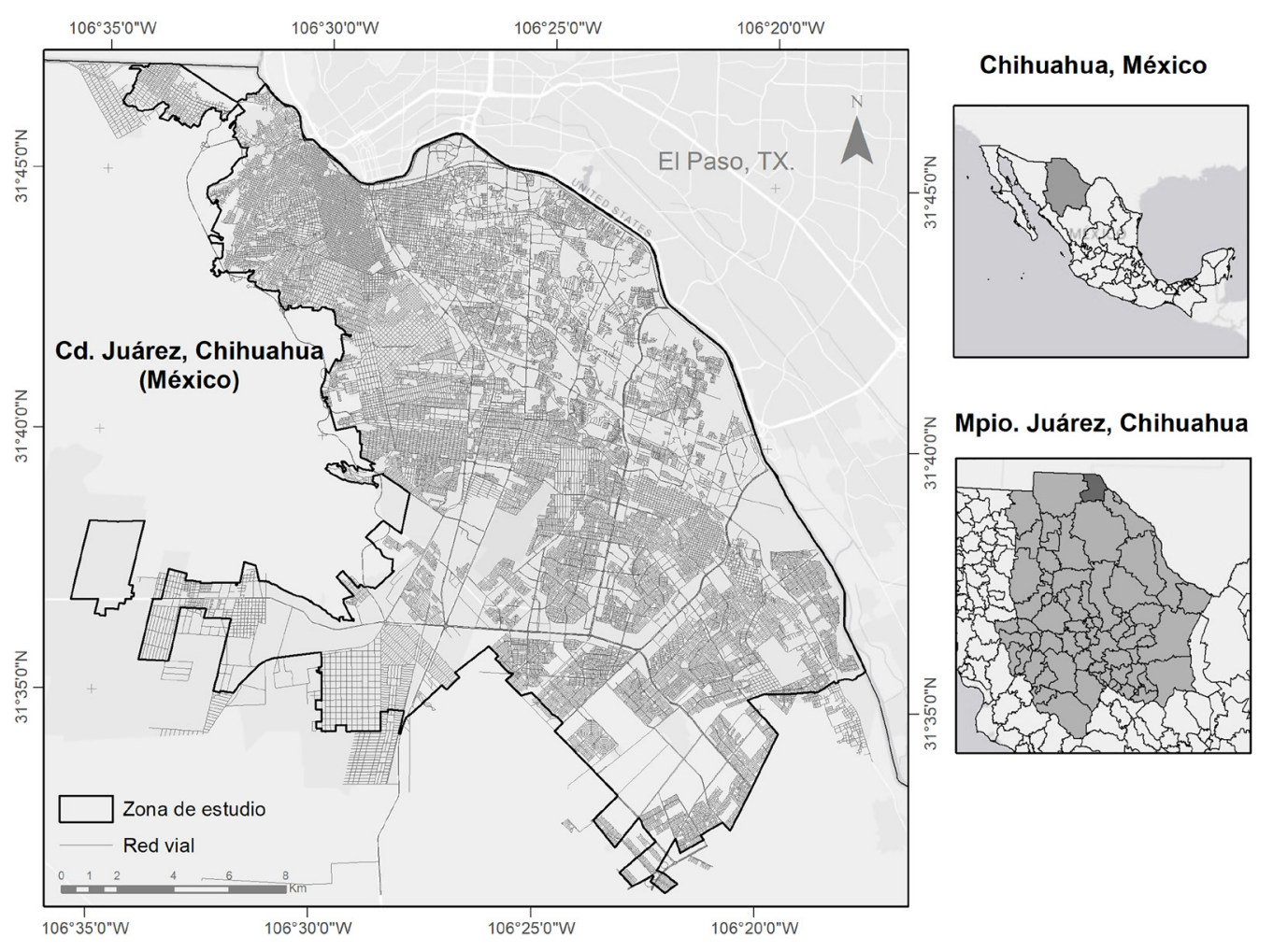

FIGURA 1. Localización del área de estudio

FUENTE: elaboración propia a partir de archivos vectoriales del Instituto Nacional de Estadística y Geografía (INEGI, 2018). 


\section{Marco teórico-conceptual}

La ciudad, visualizada como el hábitat predominante del hombre contemporáneo, ha venido sufriendo una notoria degradación ambiental y de la vida social (Alvarado et al., 2017), mientras que las áreas públicas que frecuentamos para el ocio, los deportes, la recreación y el desplazamiento cotidiano plantean importantes aspectos en la relación físico-espacio social (Cardona, 2008). Las ciudades del siglo XXI tienen el reto de cohesionar los tejidos urbanos allí donde la desocupación o el deterioro haya podido generar vacíos de actividad, de integrar las nuevas actuaciones, tanto si se trata de rehabilitaciones como de obra nueva, en los tejidos urbanos existentes, y de garantizar la accesibilidad a los servicios y equipamientos necesarios para el desarrollo de la vida en sociedad de forma sostenible (Asensi, 2015). Uno de esos equipamientos indispensables es el espacio público. El espacio público se define como un sitio de uso colectivo

[...] es el ámbito en el que los ciudadanos pueden (o debieran) sentirse como tales, libres e iguales. Es donde la sociedad se escenifica, se representa a sí misma, se muestra como una colectividad que convive, que muestra su diversidad y sus contradicciones y expresa sus demandas y sus conflictos. Es donde se construye la memoria colectiva y se manifiestan las identidades múltiples y las fusiones en proceso (Borja, 2011, p. 39).

Es considerado el recurso común más importante en las ciudades, ya que se define día a día con el actuar y el uso cotidiano de los ciudadanos (Campos \& Brenna, 2015), sin embargo, el interés por este tipo de sitio ha disminuido debido a que no todos tienen un fácil acceso, además de que existen motivos como la delincuencia, el descuido o el desinterés por parte de los ciudadanos y de las autoridades, así como dificultades de movilidad o económicas (Fonseca, 2014). Lo anterior evidencia un problema de justicia social para lograr acceder a todos los lugares de esparcimiento en condiciones adecuadas y con equipamientos dignos para poder desempeñar actividades físicas y de recreación, esparcimiento y ocio.
Cuando los espacios públicos urbanos reúnen las condiciones apropiadas y se pueden realizar actividades deportivas diversas, se convierten en auténticos generadores de redes sociales que contribuyen a garantizar la cohesión social de la ciudadanía y, en consecuencia, mejoran la calidad de vida de los usuarios (Puig et al., 2006). La calidad de vida debe ser abordada desde los ámbitos ambiental, social, político, cultural e individual, por lo tanto, el diseño urbano y ambiental influye sobre los índices de calidad en las poblaciones. $\mathrm{Al}$ impulsarse el desarrollo de ciudades saludables de manera directa se impacta en la calidad de vida de las personas, ya que se les reivindica su derecho ciudadano de contar con un lugar urbano que promueva y proteja su medio tanto en el ámbito ambiental como mental, físico y social (Urbina, 2014).

La justicia social es un concepto complejo que ha evolucionado en el tiempo y ha sido abordado desde diferentes disciplinas como la economía y la filosofía política, y también ha transitado por criterios de justicia distributiva de bienes, de recursos, de capacidades y de participación, lo que implica múltiples dimensiones y hace difícil el planteamiento de un concepto único e incluyente de los diferentes criterios inherentes a la justicia social (Murillo \& Hernández, 2011). En este artículo, se conceptualiza la justicia social como "el conjunto de decisiones, normas y principios considerados razonables que implica equidad, dignidad humana y la no exclusión, donde las personas tienen las mismas oportunidades y derechos que se ejercen con la responsabilidad y valoración de la individualidad, pero también del bienestar colectivo" (Romo, 2007, p. 18), de manera que entre los objetivos de "hacer ciudad" está el distribuir equitativamente los espacios públicos en el territorio urbano, permitiendo el acceso y disfrute de las personas a este equipamiento y los servicios provistos por ellos.

En relación con el derecho que deben tener todos los habitantes en la ciudad, es fundamental el acceso a mejor calidad de vida y al desarrollo social (Pérez \& Romo, 2019), que son aspectos necesarios que se 
deben considerar cuando se trata de promover la inclusión social y la promoción de un estilo de vida activo; de lo contrario, el deterioro, la invasión o la escasez de los espacios en la ciudad, principalmente públicos, interfieren en su apropiación, uso y disfrute (Cardona, 2008). En lo ambiental, la calidad, la cantidad y la equidad en la distribución de las áreas verdes, representadas en parques, plazas y jardines, así como las que están ubicadas en las calles, y las áreas públicas libres de suciedad, las zonas de confort térmico y con una calidad de aire apropiada y libre de olores desagradables, son aspectos que deben ser considerados y que además ponen en evidencia lo mucho que se tiene que hacer en materia de habitabilidad urbana (Alvarado et al., 2017).

La búsqueda de la ciudad ideal y los lugares para el encuentro resurge a partir de problemas netamente urbanos como la contaminación del ambiente, la pobreza y la informalidad urbana, la escasez del agua, la inseguridad, la falta de transporte adecuado y el tráfico caótico, que son fenómenos que adquieren perfiles particulares de acuerdo con el nivel socioeconómico y cultural de los grupos sociales (Campos \& Brenna, 2015). Las áreas urbanas deben ser valoradas no solo con el criterio de funcionalidad arquitectónica, sino también con el de vivencialidad y apropiación que estas que puedan propiciar su potencial para ser incorporadas por el sujeto (Cardona, 2008), por ello se pone en evidencia el valor de los parques como sitios de referencia de la planificación urbana asociada al deporte en el espacio público (Magrinyá \& Mayorga, 2008).

Asegurar la justicia social en relación con el equipamiento urbano es fundamental, ya que de ello deriva una adecuada apropiación de los espacios públicos para desarrollar actividades físicas que beneficien al individuo y, de forma primordial, su salud; sin embargo, en la mayoría de las ciudades en México no se tienen las condiciones adecuadas para que todos los habitantes puedan acceder de igual forma a las diferentes partes con las que cuenta la ciudad, y en la mayoría de las ocasiones esto sucede en las grandes ciudades.

En cuanto a la accesibilidad, este concepto es básicamente una propiedad del urbanismo, que se refiere a edificación, transporte y medios de comunicación para facilitar la autonomía personal, independientemente de la edad y las condiciones físicas de cada persona, para acceder a diferentes espacios. El concepto es utilizado para nombrar el grado en el que todas las personas, más allá de sus capacidades físicas o técnicas, pueden utilizar un cierto objeto o acceder a un servicio, además de suponer un derecho que otorga a una persona la real posibilidad de ingresar, transitar y permanecer en un lugar de forma segura, autónoma y confortable (Simian, 2014). No todas las personas tienen un fácil acceso a los espacios públicos y tampoco hay suficientes en las ciudades, por este motivo es en estos sitios donde se centralizan las distintas actividades que diversos grupos o individuos desean realizar, apropiándose de cierta manera de estos para poder realizarlas (Fonseca, 2014).

Respecto a la marginación y los espacios públicos, en general México es considerado un país con grandes contrastes y desigualdades económicas y sociales: mientras que una pequeña élite domina en términos de poder económico, la gran mayoría de la población vive al margen del desarrollo económico, social y humano (Hernandez, 2015). En contextos urbanos en los que prevalecen condiciones de pobreza, las acciones gubernamentales del ámbito local se orientan actualmente no solo a modificar las condiciones materiales de los espacios públicos degradados, sino a favorecer la organización de la vida comunitaria (Mier y Terán et al., 2012). Lamentablemente, es frecuente que la mala calidad del sitio propicie una percepción de inseguridad que incita al abandono de lo público y de lo colectivo, que a su vez deriva en la pérdida de interés por el intercambio social (Caquimbo et al., 2017).

Existen índices de desigualdad social, como el índice de marginación urbana del Consejo Nacional 
de Población (Conapo $)^{4}$ y el de nivel de bienestar del Consejo Nacional de Evaluación de la Política de Desarrollo Social (Coneval) $)^{5}$, que muestran cuándo los bienes del desarrollo no llegan de la misma forma a toda la población y a partir de ellos se aplica el concepto de marginación a través de componentes de educación, salud, condiciones y bienes de vivienda e ingreso. Se entiende la marginación como una serie de carencias definidas en múltiples dominios, como las oportunidades de participación en las decisiones colectivas y los mecanismos de apropiación de recursos de las titularidades de derechos que permiten el acceso al capital físico, humano y social, entre otros.

Una característica común en los asentamientos marginales es la ausencia de un espacio público que facilite la vida en comunidad (Caquimbo et al., 2017). Cuando se habla de planear actividades en la ciudad que convoquen a la comunidad a la participación en entornos para el deporte y la recreación, se hace innegable la necesidad de pensar en estos sitios como lugares de calidad e incluyentes; por lo tanto, es importante referirse a la suficiencia de lugares y sus condiciones específicas (Stuart, 2011). En un contexto de creciente desigualdad y exclusión social para grandes mayorías, los espacios públicos juegan un papel de primordial importancia, ya que cumplen importantes funciones sociales y urbanas (Mier y Terán et al., 2012).

En variadas ocasiones el lugar público no es un lugar protegido, pues en algunos casos no está diseñado para dar seguridad, sino para cumplir funciones como

4 El Conapo en México presenta periódicamente los resultados del índice de marginación a nivel municipal y a nivel intraurbano y tiene como misión "la planeación demográfica del país a fin de incluir a la población en los programas de desarrollo económico y social que se formulen dentro del sector gubernamental y vincular sus objetivos a las necesidades que plantean los fenómenos demográficos" (Conapo, 2019).

5 El Coneval tiene como funciones principales: “1) normar y coordinar la evaluación de la Política Nacional de Desarrollo Social y las políticas, programas y acciones que ejecuten las dependencias públicas. 2) Establecer los lineamientos y criterios para la definición, identificación y medición de la pobreza, garantizando la transparencia, objetividad y rigor técnico en dicha actividad". A través de indicadores específicos, evalúa el rezago social y diferentes tipos de pobreza (Coneval, 2021). transitar, lo cual lleva a que los sitios no protegidos se vean apropiados por las llamadas "clases peligrosas de la ciudad": pobres, marginados, indigentes, delincuentes, etc. Esto conlleva que el espacio público sirva como reflejo de los problemas de injusticia social, económica y política, y que a su vez provoque el miedo de algunas personas, la marginación y la violencia urbana (Fonseca, 2014). Las pocas zonas públicas de las que se dispone en los sitios con marginación se caracterizan además de su escasez y por lo inhóspito, ya que generalmente se trata del peor suelo, aquel que es menos aprovechado, y de esa forma se convierten en muchos casos en áreas de segregación social (Caquimbo et al., 2017).

Los habitantes de los barrios populares son conscientes de la importancia que tiene el contar con lugares para la recreación y el esparcimiento cerca de sus viviendas y logran percibir la disminución de violencia cuando los jóvenes tienen lugares para practicar deportes y los niños pueden jugar sin encontrarse en riesgo (Caquimbo et al., 2017).

Existe diferentes dimensiones por considerar sobre la marginación y el espacio público, entre las cuales Cortés (2006) refiere las siguientes:

1. Dimensión ecológica. Los marginales tienden a ser segregados a entornos con carencias ambientales y territoriales o ser recluidos en zonas deterioradas en las ciudades.

2. Dimensión sociopsicológica. En relación con su bienestar, entendido en sentido subjetivo (por ejemplo, de un nivel de satisfacción personal adecuado que los lleve a superar su condición por sí mismos).

3. Dimensión sociocultural. En capital físico o humano y en mecanismos de apropiación o de titularidades sobre recursos, que entre otras cosas provocan incertidumbre respecto al acceso a satisfactores básicos (salud, educación y vivienda). 
4. Dimensión económica. En ingresos (flujos monetarios o no monetarios suficientes para adquirir ciertos satisfactores) y en bienes de consumo (por ejemplo, una canasta de factores alimenticios y no alimenticios).

5. Dimensión política. En oportunidades de participación en los mecanismos de decisión colectiva o política que le dan voz a la ciudadanía en la representación de sus intereses.

Es importante que en los nuevos desarrollos se consideren las dimensiones referidas y se tenga en cuenta que los espacios públicos de gran tamaño tienen dificultades de apropiación por parte de las comunidades, además de que en los planes parciales para desarrollar en los diversos sectores de la ciudad con déficit de este tipo de sitios se debe contemplar la posibilidad de aumentar la exigencia del porcentaje que es destinado para tal uso. No es suficiente realizar intervenciones físicas en el área pública, es necesario que se propongan programas complementarios dirigidos al incremento del uso adecuado de dichos sitios con la finalidad de fomentar la vinculación de los miembros de la comunidad (Ceballos, 2008). El espacio público ha perdido lugar en el concierto urbano, ya sea a través de la recuperación de su concepción filosófica o política o bien desde la visión social urbana territorial; sin embargo, la discusión teórica no da elementos para solucionar su problemática, aun cuando está identificada y aunque su relevancia y significado pueda ser defendible (Hidalgo, 2017).

La ausencia de reconocimiento del derecho al espacio público ha favorecido la exclusión, la pérdida de identidad comunitaria y comunicación, la segregación, la carencia de monumentalidad y belleza, movilidad y accesibilidad, la privatización, la fragmentación y la inseguridad, además de limitar la práctica del deporte, la recreación y la participación, por lo cual sin este tipo de lugar accesible a toda la población difícilmente se puede hablar de democracia, calidad de vida, igualdad y solidaridad (López, 2012). De igual forma, López (2012) también menciona que el derecho al espacio público surge como una respuesta a la búsqueda de una mejor calidad de vida y en virtud de generar garantías para su protección y recuperación, ya que se trata de un derecho emergente-colectivo.

La pobreza urbana y las situaciones de carencia y precariedad de bienes y servicios en los barrios populares de las ciudades van más allá de las necesidades básicas de alimentación e implican la dificultad de la población de menores recursos para responder a las pautas y exigencias que establece la sociedad urbana para participar e integrarse a ella (Mier y Terán et al., 2012). Además, la pobreza urbana no solo debe hacer referencia a la capacidad de pago que tienen los trabajadores y sus familias para lograr acceder a los bienes que se ofertan en el mercado, sino que también se refiere al nivel de vida y a la oferta diferenciada de bienes públicos que se les ofrecen en la sociedad local (Mier y Terán et al., 2012).

Constantemente aparecen asentamientos marginales como expresión de un hábitat precario, cuyo proceso de consolidación carece del acondicionamiento y el conocimiento necesario para su incorporación a la ciudad y para su verdadera rehabilitación, expresando así una desigualdad urbana en donde prevalece la inestabilidad y la inseguridad en la vida social. De esta forma, se genera la desintegración de los espacios públicos vivos y la gradual transformación de las calles en zonas sin interés alguno para nadie, ya que son factores que contribuyen al vandalismo y la delincuencia en la ciudad (Guzmán et al., 2015). Mier y Terán et al. (2012) plantean que el ideal de construir espacios públicos para promover una mejor convivencia comunitaria y mejorar la cohesión social requiere de políticas sociales urbanas que sean integradas y además que estén basadas en el reconocimiento de los derechos ciudadanos, así como en la capacidad organizativa y en las relaciones de corresponsabilidad que los ciudadanos establezcan con las instituciones gubernamentales que se encargan de ejercer las políticas sociales. 


\section{Materiales y métodos}

\subsection{Inventario de espacios públicos}

Los datos analizados en el trabajo de Romo (2007) y los proporcionados por el Instituto Municipal de Investigación y Planeación (IMIP, 2017) permiten mostrar la distribución espacial de las diversas áreas públicas en Ciudad Juárez. Para este artículo y de acuerdo con la conceptualización presentada en la sección del marco teórico-conceptual, los tipos de espacios públicos aquí considerados son: parques, plazas, gimnasios municipales, unidades deportivas y estadios, que representan un total de 2.578 registros, donde la mayoría corresponde a parques. La Figura 2 muestra que los parques y las unidades deportivas se encuentran distribuidos aparentemente en la mayor parte de la ciudad, sin embargo, los estadios, los gimnasios municipales y las plazas se concentran al norte cercano a la frontera, mientras que la zona sur-poniente es la que mayormente carece de espacios públicos.

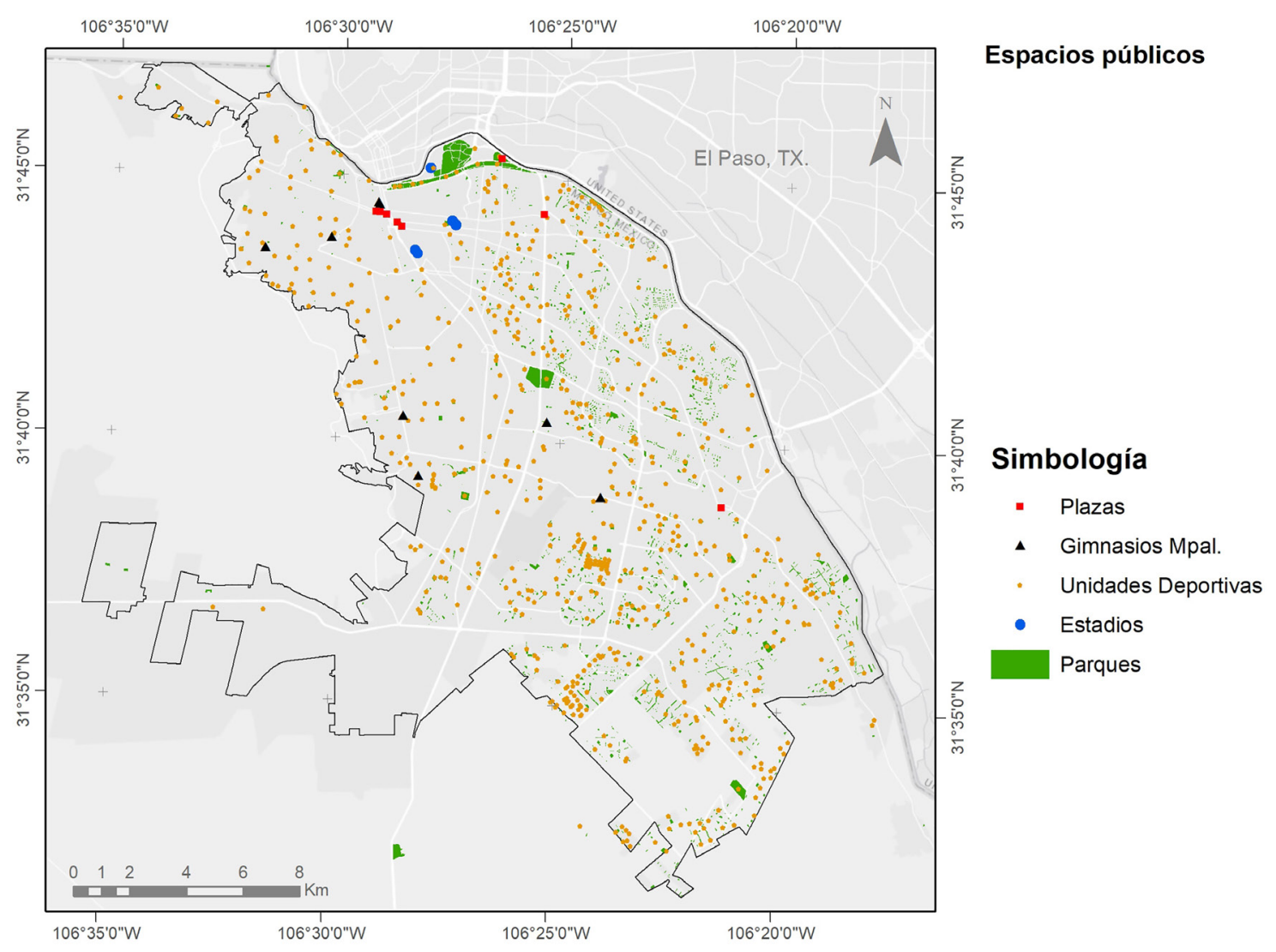

FIGURA 2. Espacios públicos en Ciudad Juárez, Chihuahua

FUENTE: elaboración propia a partir de la base de datos IMIP (2017).

\subsection{Análisis de accesibilidad}

La accesibilidad se refiere al grado o nivel de acceso que tienen las personas en un tiempo y lugar determinado a los sitios públicos abiertos (Harrison et al., 1995). Para el caso de estudio, se tomó la accesibilidad definiendo un área de servicio para cada espacio público para conocer la cobertura que tiene cada área geoestadística básica (AGEB), considerando que las personas se transportan desde sus hogares caminando (Figueroa, 2008).

Se utilizó el software ArcGIS con la herramienta Network Analyst, considerada como una técnica 
más sofisticada que la aplicación de un buffer debido a que toma en cuenta el área de influencia o de servicio en función de la red vial (Handley et al., 2003). Las áreas de servicio se definieron a partir de la metodología propuesta por Figueroa (2008), la cual establece las áreas de servicio a partir de estándares internacionales. El primero es de English Nature y considera que las personas deben vivir a 300 metros de distancia de un sitio de 2 ha (Handley et al., 2003), similar a 5 minutos caminando, mientras que el segundo estándar es de la Agencia de Medio Ambiente de la Unión Europea, que señala que las personas deben estar como máximo a 900 metros, lo que corresponde a 15 minutos caminando (Barbosa et al., 2007).

De acuerdo con los estándares internacionales adaptados al contexto en ciudades latinoamericanas y siguiendo las recomendaciones de Figueroa (2008), en la adaptación del estándar a la realidad local se definieron dos criterios de análisis: el primero incluye los espacios públicos clasificados como parques, plazas, gimnasios municipales, unidades deportivas y estadios iguales o mayores a $1.000 \mathrm{~m}^{2}$ porque se considera el tamaño mínimo aceptable para que preste los servicios de recreación y ocio a la población. Para este tipo se estableció un área de servicio de 300 metros.

En el segundo criterio se seleccionaron los espacios públicos iguales o mayores a $5.000 \mathrm{~m}^{2}$, ya que los servicios ecológicos que prestan son mucho mayores. Para este tipo se determinó un área de servicio o acceso de 900 metros caminando (15 minutos), tomando en cuenta que hay servicios ecológicos y sociales que requieren una superficie mayor para el disfrute de la naturaleza, caminatas y actividades recreativas y deportivas, entre otras (Figueroa, 2008). El objetivo de establecer dos criterios de análisis de acuerdo con el tamaño del área verde y la distancia desde el hogar es adaptarse a la realidad de las ciudades latinoamericanas, ya que son las que determinan las funciones o servicios que cumplen diferentes tipos de espacios públicos o áreas verdes.

\subsection{Análisis espacial que relaciona la accesibilidad a espacios públicos y la distribución territorial de la marginación}

Para el análisis de accesibilidad a espacios públicos y la distribución territorial de la marginación se consideraron 5 AGEB delimitadas por el Instituto Nacional de Estadística y Geografía (INEGI), seleccionadas a partir de las clases del índice de marginación urbana (IMU) establecidas por el Consejo Nacional de Población (Conapo, 2010), y se eligió el AGEB localizada en la mediana de cada una de las 5 categorías con la finalidad de identificar la distribución en contextos de marginación desde muy bajos hasta muy altos de acuerdo con el estrato socioeconómico.

Para ello se tomó como muestra el AGEB 3478 con un IMU muy bajo de -1,1608 localizado en al norte de la ciudad; el AGEB 6966 con el IMU bajo de -0,8285 al centro-poniente; el AGEB 4508 con el IMU medio de -0,3322 localizado al centro-poniente; el AGEB 489A con un IMU alto de 0,3660 al norponiente de la ciudad; y el AGEB 5525 con el IMU muy alto de 1,4932 localizado al sur-poniente de Ciudad Juárez. Posteriormente se realizó la intersección de las 5 zonas de muestra y las 2 áreas de servicio de los espacios públicos en 300 y 900 metros con la finalidad de identificar la superficie de cobertura de accesibilidad en las 5 AGEB.

\section{Resultados}

\subsection{Accesibilidad a espacios públicos}

Como primera observación, se identificó la cobertura de la superficie de los espacios públicos por AGEB, donde se destaca que en 228 de las 631 AGEB en Ciudad Juárez no existe este tipo de sitios. Por el contrario, existen zonas como las localizadas en el Parque 
Central y el Parque Chamizal, considerados como los más importantes a nivel ciudad (Figura 3), en donde la superficie cubre más del 54\%, o la zona del Club Campestre, que es considerado un lugar privado, si bien la mayor parte de la ciudad que cuenta con lugares públicos se encuentra en el rango de 0,01\% a $5,9 \%$ en cuanto a la superficie que ocupan dentro del AGEB.

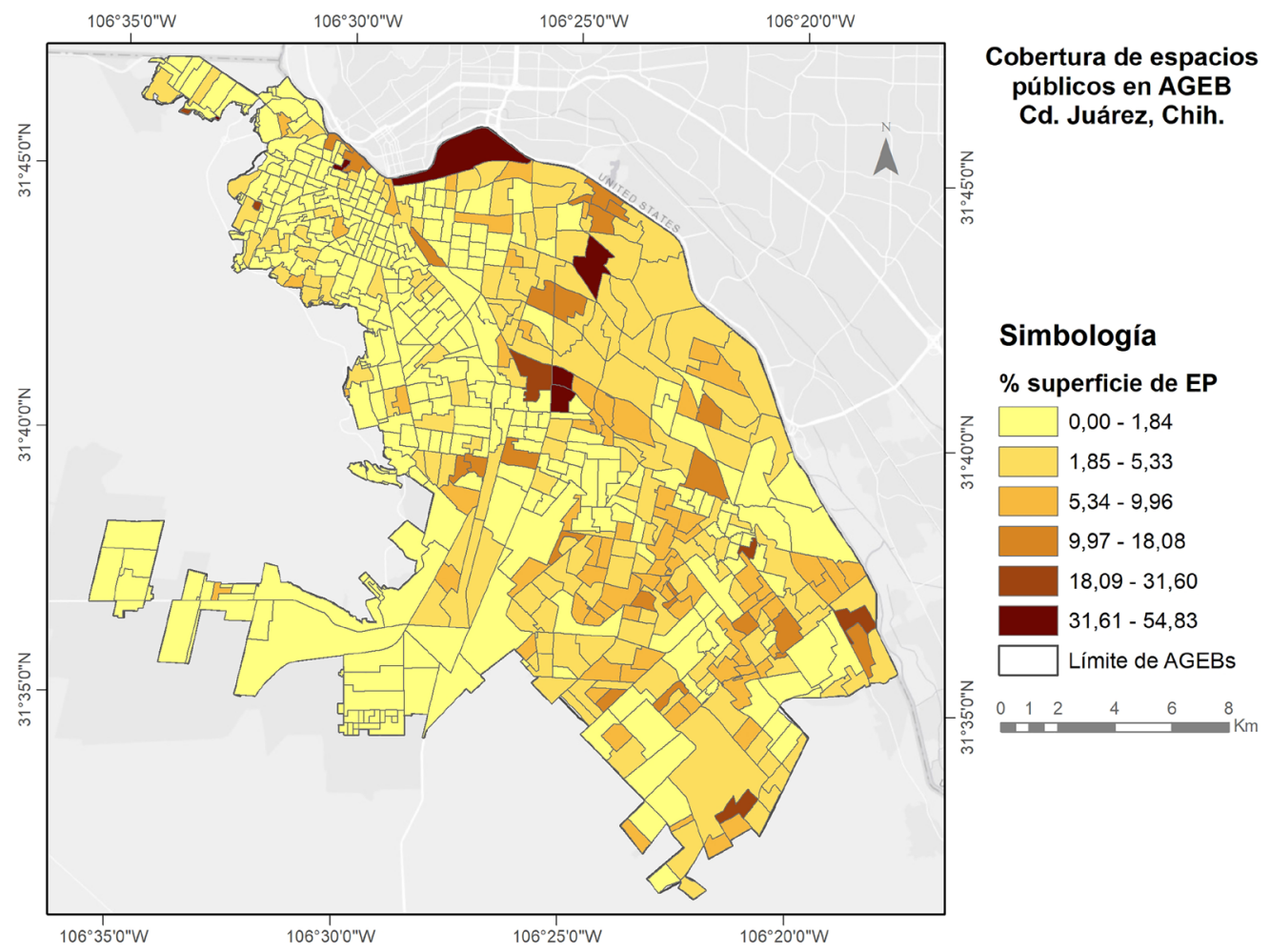

FIGURA 3. Cobertura de superficie de espacios públicos por AGEB

FUENTE: elaboración propia a partir de archivos vectoriales de INEGI y datos del Censo de Población y Vivienda (INEGI, 2010).

A partir de la generación de las áreas de accesibilidad en Network Analyst (Figura 4), tomando en consideración que la superficie del área de estudio es de $35.049,9$ ha, se pudo identificar a nivel ciudad que los espacios públicos con superficie mayor a los $5.000 \mathrm{~m}^{2}$ tienen un área de servicio de 19.667,6 ha (1.371 sitios), lo que representa un 56,11\% de cobertura, donde la zona sur-poniente es la que carece mayormente del acceso a estos. Por otro lado, los lugares con superficie entre los 1.000 y $5.000 \mathrm{~m}^{2}$ (454) tienen un área de servicio de 9.772,39 ha, que represen el 27,88\% en accesibilidad. Además, existen zonas donde existe sobreposición de la accesibilidad en los dos estratos, que representan 7.861,39 ha, lo que significa que el 22,42\% del área de estudio tiene mayor posibilidad de acceder a un espacio público tanto en el rango de 300 metros como de 900 metros.

Para el análisis no se toman en cuenta las áreas menores a $1.000 \mathrm{~m}^{2}$, que representan una totalidad de 753 polígonos que no se consideran apropiados para el encuentro social y la interacción de los habitantes. Por el contrario, una superficie de $13.471,35$ ha no tiene acceso a ningún espacio público (38,43\%), lo cual evidencia que no existe justicia socioterritorial y que se presenta una distribución desigual de los sitios públicos en Ciudad Juárez. 


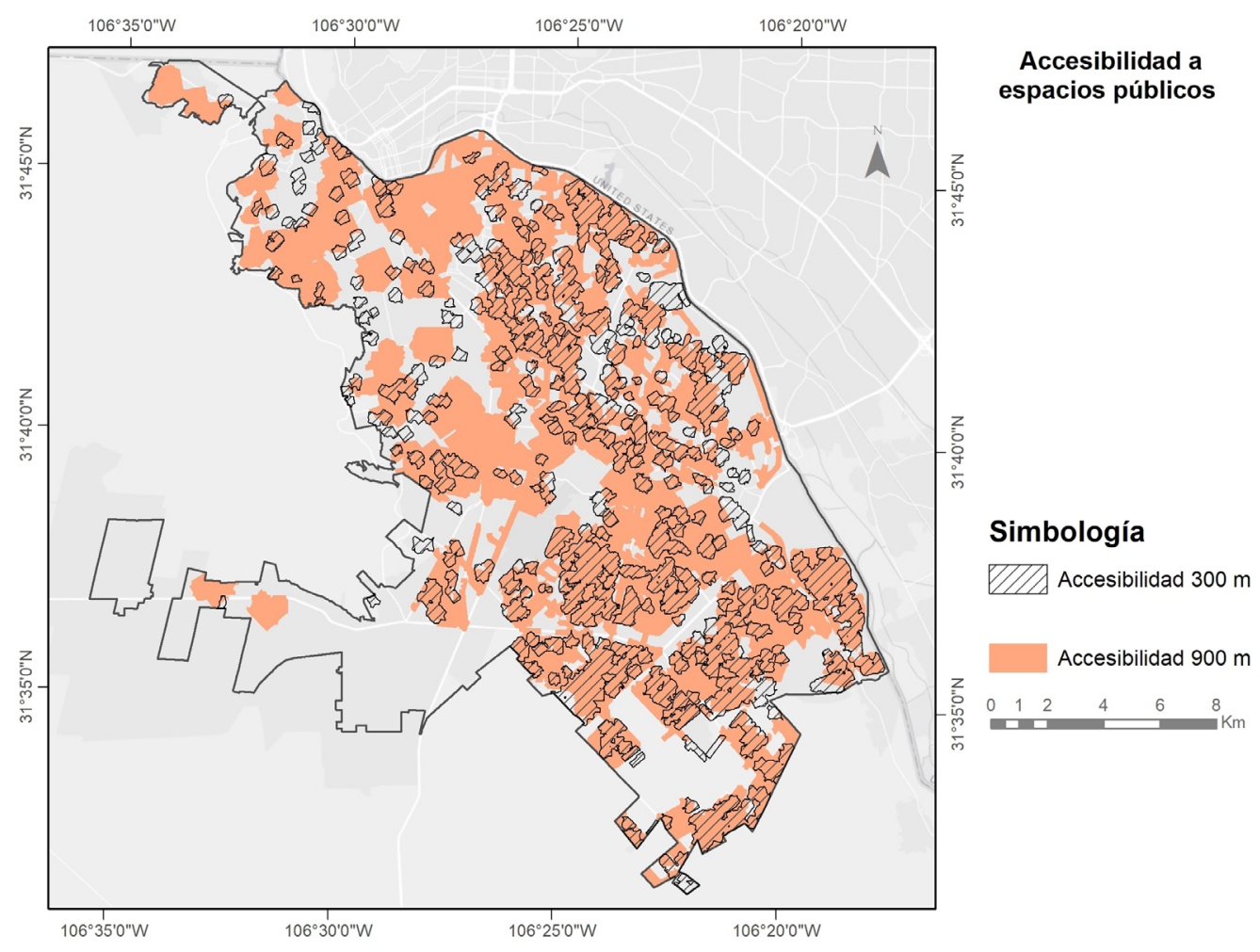

FIGURA 4. Accesibilidad a espacios públicos

FUENTE: elaboración propia a partir de información vectorial de INEGI.

\subsection{Análisis espacial de accesibilidad a espacios públicos y distribución territorial de la marginación}

En Ciudad Juárez existen 631 AGEB, de las cuales se clasifican 27 con un IMU muy alto y albergan una totalidad de 15.495 personas que se encuentran concentradas principalmente en colonias del sur-poniente de la ciudad (Conapo, 2010).

Por otro lado, la clasificación del IMU con valores altos agrupa una totalidad de 56 AGEB, una población de 99.910 y se localizan en el norponiente de Ciudad Juárez; el IMU medio agrupa una totalidad de 273 AGEB con una población de 642.874 distribuidos en el poniente y suroriente de la ciudad; posteriormente se encuentra el IMU bajo con 102 AGEB y una población de 308.055 concentrados en la zona centro y al sur, mientras que el IMU en la clasificación muy bajo agrupa 95 AGEB con 253.432 habitantes concentrados en la zona nororiente y centro norte de la ciudad.

Finalmente existen 78 AGEB que no tienen datos porque no cuentan con población, ya que se trata de parques industriales, la zona del aeropuerto y el Parque Chamizal o bien son áreas con una población mínima de la que no se tienen suficientes registros, que no es tomada en cuenta para poder obtener los IMU y representa 1.238 habitantes localizados en zonas de la periferia. La marginación urbana en Ciudad Juárez es muy notable y gráficamente se puede observar esa distribución y concentración de estratos en la Figura 5. 


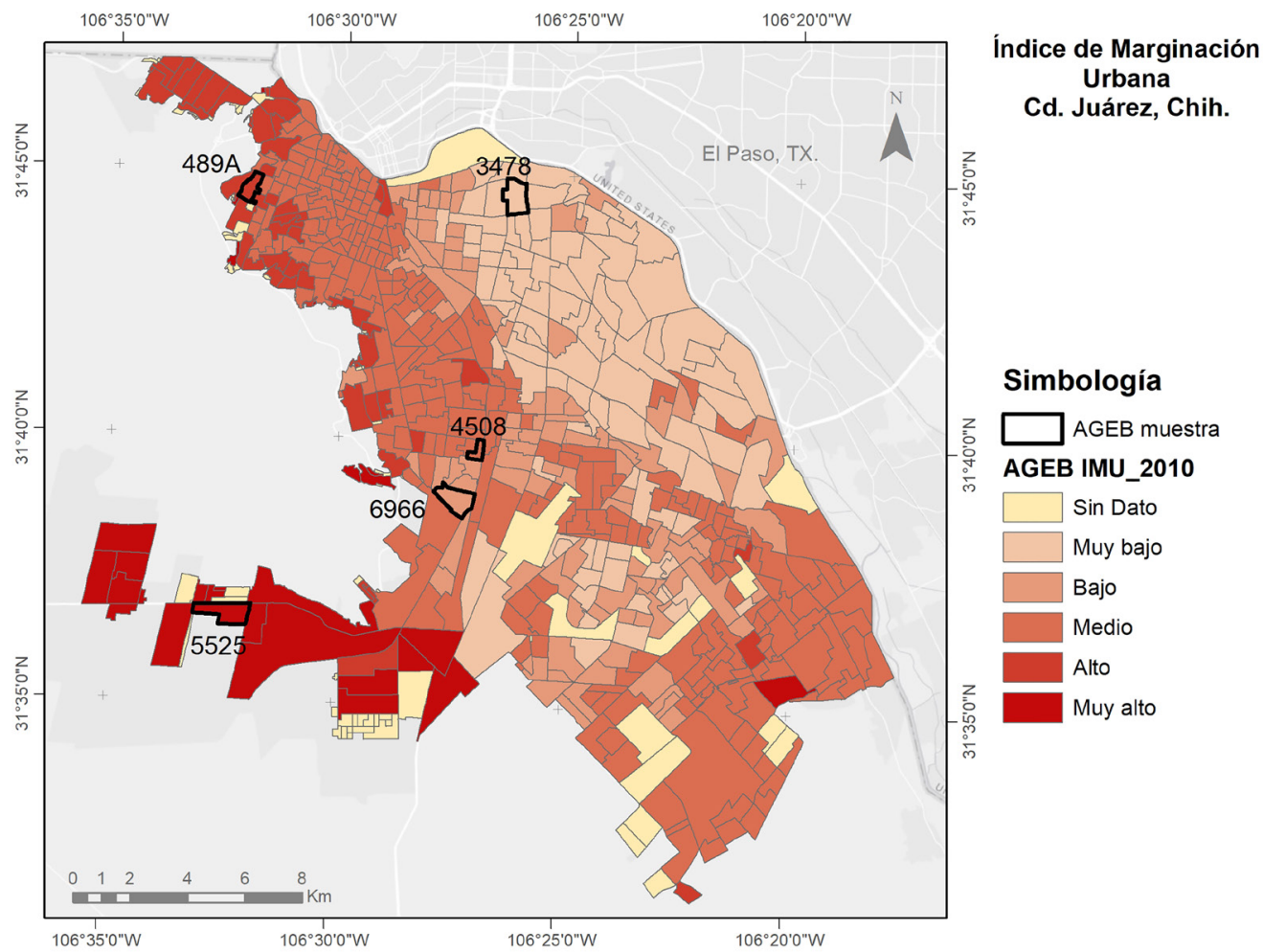

FIGURA 5. Índice de marginación urbana en Ciudad Juárez

FUENTE: elaboración propia a partir de la información sobre marginación del Consejo Nacional de Población (Conapo, 2010).

$\mathrm{Al}$ realizar el análisis en las 5 zonas de muestra, se puede identificar que dentro de las áreas seleccionadas existe una aparente relación entre el índice de marginación urbana y el número de espacios públicos, ya que el AGEB con un índice muy bajo de marginación es el que mayor número de espacios públicos tiene y comienza a disminuir (Tabla 1) hasta las zonas en donde la marginación es muy alta. Sin embargo, el análisis de accesibilidad no toma en cuenta las áreas menores a $1.000 \mathrm{~m}^{2}$, ya que son consideradas como jardines y no cumplen con la suficiente superficie en donde se puedan desarrollar actividades deportivas o de recreación. Hay que señalar también que ello no significa que los estratos que no cuentan con áreas públicas no puedan tener acceso a estas, ya que se pueden encontrar en los límites de otras zonas en donde sí los hay.

\begin{tabular}{|c|c|c|c|c|c|c|c|c|c|c|}
\hline \multirow{2}{*}{$\begin{array}{c}\text { Espacios } \\
\text { públicos }\left(\mathrm{m}^{2}\right)\end{array}$} & \multicolumn{2}{|c|}{$\begin{array}{c}\text { AGEB } 3478 \\
\text { IMU muy bajo }\end{array}$} & \multicolumn{2}{|c|}{$\begin{array}{l}\text { AGEB } 6966 \\
\text { IMU bajo }\end{array}$} & \multicolumn{2}{|c|}{$\begin{array}{l}\text { AGEB } 4508 \\
\text { IMU medio }\end{array}$} & \multicolumn{2}{|c|}{$\begin{array}{c}\text { AGEB 489A } \\
\text { IMU alto }\end{array}$} & \multicolumn{2}{|c|}{$\begin{array}{c}\text { AGEB } 5525 \\
\text { IMU muy alto }\end{array}$} \\
\hline & $N^{\circ}$ & Área $\mathrm{m}^{2}$ & $\mathrm{~N}^{\circ}$ & Área $\mathrm{m}^{2}$ & $\mathrm{~N}^{\circ}$ & Área $\mathrm{m}^{2}$ & $\mathrm{~N}^{\circ}$ & Área $\mathrm{m}^{2}$ & $\mathrm{~N}^{\circ}$ & Área $\mathrm{m}^{2}$ \\
\hline$<1000$ & 10 & $5.671,1$ & 0 & 0 & 0 & 0 & 0 & 0 & 0 & 0 \\
\hline$\geq 1000<5000$ & 5 & $8.847,1$ & 4 & $8.286,89$ & 0 & 0 & 0 & 0 & 1 & $4.246,02$ \\
\hline$\geq 5000$ & 0 & 0 & 1 & $72.595,64$ & 0 & 0 & 0 & 0 & 0 & 0 \\
\hline Total & 15 & $14.518,2$ & 5 & $80.882,53$ & 0 & 0 & 0 & 0 & 1 & $4.246,02$ \\
\hline
\end{tabular}

FUENTE: elaboración propia a partir de información vectorial de INEGI y Conapo. 
El AGEB 3478 localizada al norte de la ciudad, con una superficie de 84,33 ha (Figura 6), abarca las colonias Partido Díaz y Progresista, así como los condominios Excelencia, Lausane y Residencial Villas del Bravo, fraccionamientos como el Residencial Andalucía, Los Saucos, Residencial Villa Jardín, Dunas Residencial, Querétaro, Residencial Lausane y Villas del Bravo I, además del Lienzo Charro Adolfo López Mateos, que es área de servicio, y una sección del Parque Industrial Omega. La población en el AGEB con un índice de marginación muy bajo asciende a 1.892 habitantes que representan una densidad poblacional de $22,43^{6}$ hab./ha y 7,67 $\mathrm{m}^{2}$ de área verde por habitante. El análisis de accesibilidad demuestra que existe un 21,4\% del área que no tiene cobertura de espacios públicos en el rango de 300 y 900 metros, y aunque en la zona no existen sitios como parques de gran proporción, existen áreas alrededor que proporcionan ese servicio y favorecen la cobertura.

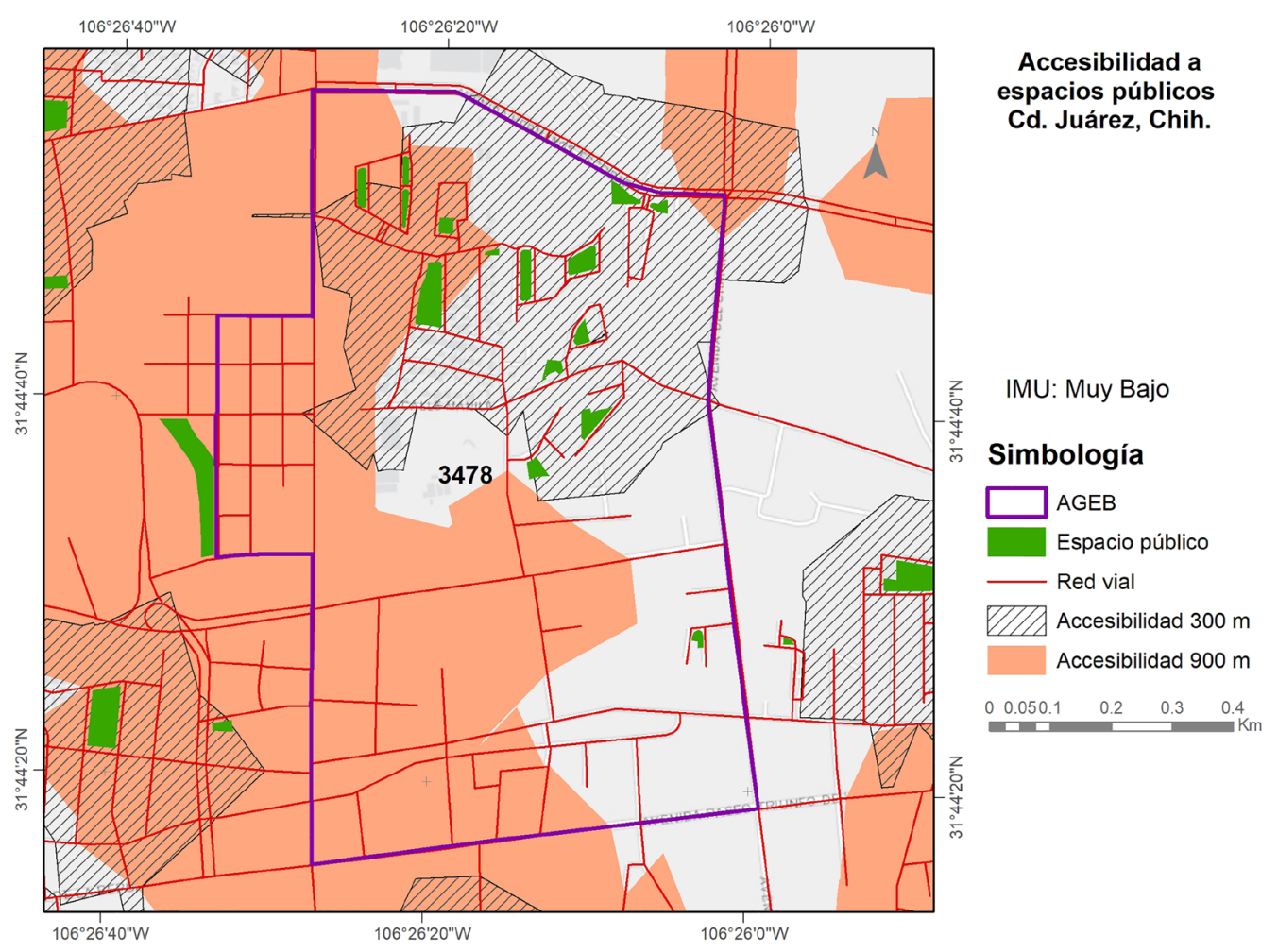

FIGURA 6. Accesibilidad a espacios públicos en zona de muy baja marginación: AGEB 3478 FUENTE: elaboración propia.

El AGEB 6966, con una superficie de 88,31 ha (Figura 7), abarca la colonia 12 de Julio y una sección de los fraccionamientos Praderas de los Oasis I y II, además del Parque Industrial North Gate. La población en el AGEB con índice de marginación bajo es de 5.275 habitantes, que representan una densidad de 59,73 hab./ha y 15,33 m² de área verde por habitante.
El análisis de accesibilidad establece que el 38,16\% del área no tiene cobertura de espacios públicos (Tabla 2), por lo cual es considerado el segundo con mayor área sin servicio a pesar de tener la cantidad más elevada de área verde por habitante, lo que se puede atribuir a la presencia de un parque industrial de una gran extensión en la zona. 


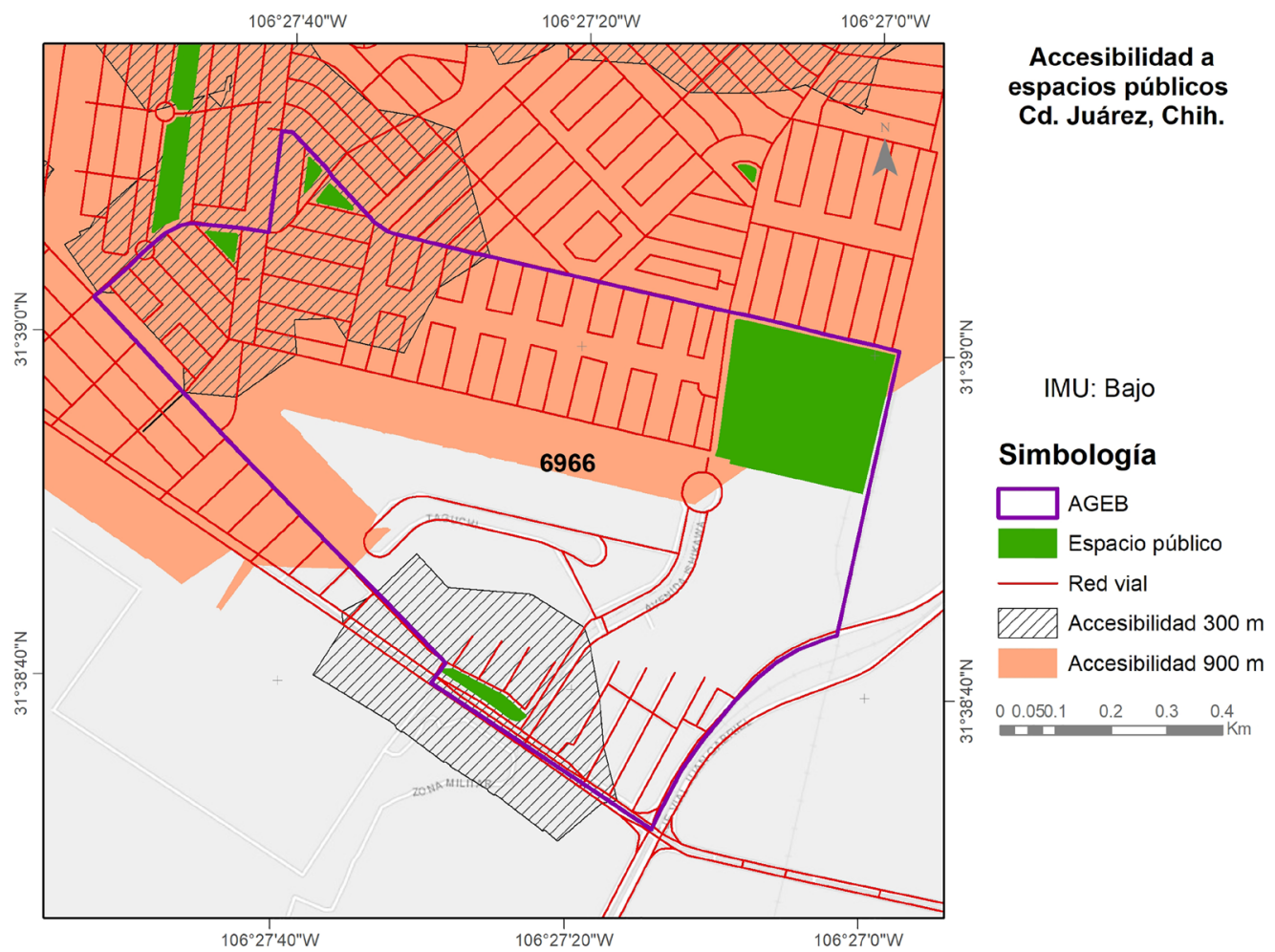

FIGURA 7. Accesibilidad a espacios públicos en zona de marginación baja: AGEB 6966 FUENTE: elaboración propia.

ElageB4508,conunasuperficiede23,58ha(Figura8), abarca una sección de la colonia División del Norte. En esta área de marginación media existen 1.895 habitantes que representan una densidad poblacional de 80,36 hab./ha, es la zona con mayor densidad de las cinco en muestra y además tiene $0,0 \mathrm{~m}^{2}$ de áreas verdes por habitante. Sin embargo, el análisis de accesibilidad expone que a pesar de que no existen lugares públicos dentro del área, en las zonas colindantes sí los hay y tienen la suficiente cobertura para dar acceso a toda el área, por lo que se considera que es la única de las cinco AGEB que sí tiene accesibilidad (Tabla 2).

\begin{tabular}{|c|c|c|c|c|c|c|c|c|c|c|}
\hline \multirow[t]{2}{*}{ IMU } & \multirow[t]{2}{*}{ AGEB } & \multirow[t]{2}{*}{ Hab. } & \multirow{2}{*}{$\begin{array}{c}\text { Densidad de } \\
\text { población hab./ha }\end{array}$} & \multirow{2}{*}{$\begin{array}{l}\mathrm{M}^{2} \text { área verde } \\
\text { por habitante }\end{array}$} & \multicolumn{2}{|c|}{$\begin{array}{l}\text { Accesibilidad } \\
300 \mathrm{~m}\end{array}$} & \multicolumn{2}{|c|}{$\begin{array}{l}\text { Accesibilidad } \\
900 \mathrm{~m}\end{array}$} & \multicolumn{2}{|c|}{$\begin{array}{c}\text { \% área sin } \\
\text { acceso } \\
(300 \mathrm{~m} \text { y } 900 \mathrm{~m})\end{array}$} \\
\hline & & & & & $\begin{array}{c}\text { Área } \\
\text { ha }\end{array}$ & $\%$ AGEB & $\begin{array}{c}\text { Área } \\
\text { ha }\end{array}$ & $\%$ AGEB & $\begin{array}{c}\text { Área } \\
\text { ha }\end{array}$ & $\%$ AGEB \\
\hline $\begin{array}{l}\text { Muy } \\
\text { bajo }\end{array}$ & 3478 & 1.892 & 22,43 & 7,67 & 30,00 & 35,57 & 43,24 & 51,27 & 18,90 & 21,40 \\
\hline Bajo & 6966 & 5.275 & 59,73 & 15,33 & 22,69 & 25,69 & 46,18 & 52,29 & 33,70 & 38,16 \\
\hline Medio & 4508 & 1.895 & 80,36 & 0,0 & 0 & 0 & 23,58 & 100 & 0,0 & 0 \\
\hline Alto & 489A & 2.804 & 60,3 & 0,0 & 2,17 & 4,66 & 39,73 & 85,44 & 6,77 & 14,56 \\
\hline $\begin{array}{l}\text { Muy } \\
\text { alto }\end{array}$ & 5525 & 1.211 & 22,4 & 1,8 & 7,79 & 7,41 & 25,01 & 23,80 & 74,59 & 71,0 \\
\hline
\end{tabular}

FUENTE: elaboración propia. 


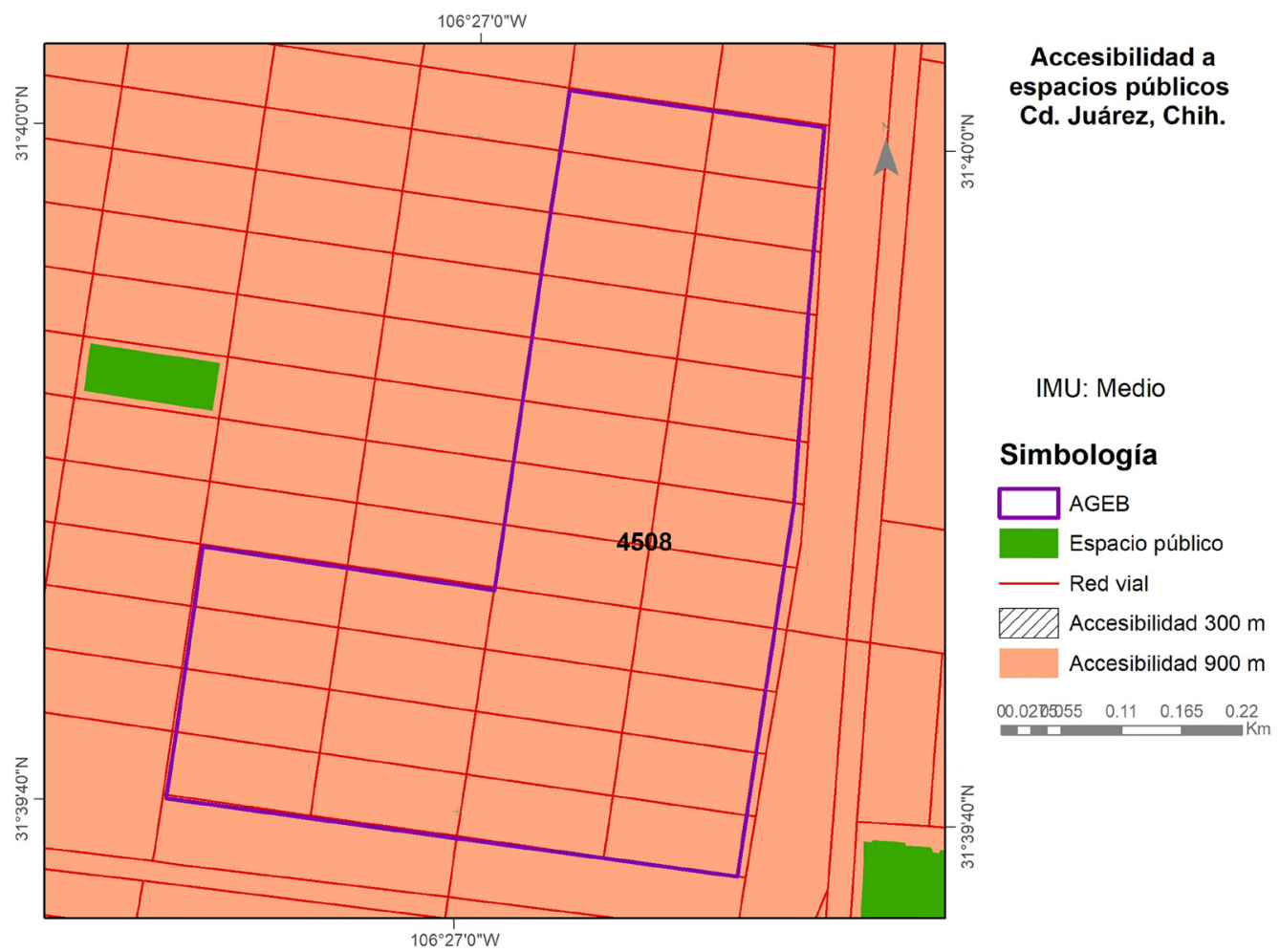

FIGURA 8. Accesibilidad a espacios públicos en zona de marginación media: AGEB 4508 FUENTE: elaboración propia.

El AGEB 489A en el norponiente de Ciudad Juárez, con una superficie de 46,5 ha (Figura 9), abarca secciones de las colonias Puerto La Paz, Renovación 92, Francisco Sarabia y Fronteriza. En esta zona de marginación alta existen 2.804 habitantes, con una densidad poblacional de 60,3 hab./ha y $0,0 \mathrm{~m}^{2}$ de área verde por habitante. El análisis de accesibilidad exhibe que, a pesar de la alta densidad de población y la nula presencia de espacios dentro del área, en las zonas adyacentes sí existen, por lo que únicamente deja el 14,56\% del área sin acceso a estos.

El AGEB 5525 al suroriente de la ciudad, con una superficie de 105,05 ha (Figura 10), se localiza entre las colonias Kilómetro 28 y Kilómetro 29 y es consi- derada una zona de marginación muy alta que alberga una población de 2.354 habitantes, lo cual genera una densidad poblacional de 22,4 hab./ha y $1,8 \mathrm{~m}^{2}$ de área verde por habitante. $\mathrm{El}$ análisis de accesibilidad demuestra que es la zona de análisis con mayor problema, donde el $71 \%$ de la superficie que no cuenta con cobertura, lo cual evidencia una coincidencia directa con el índice de marginación urbana en niveles muy altos.

Las cinco zonas tomadas como muestra para el análisis se encuentran con estándares que van desde 0,0 $\mathrm{m}^{2}$ de área verde por habitante hasta $15,33 \mathrm{~m}^{2}$, con diferente grado de accesibilidad a los espacios públicos, como se mostró en la Tabla 2. 


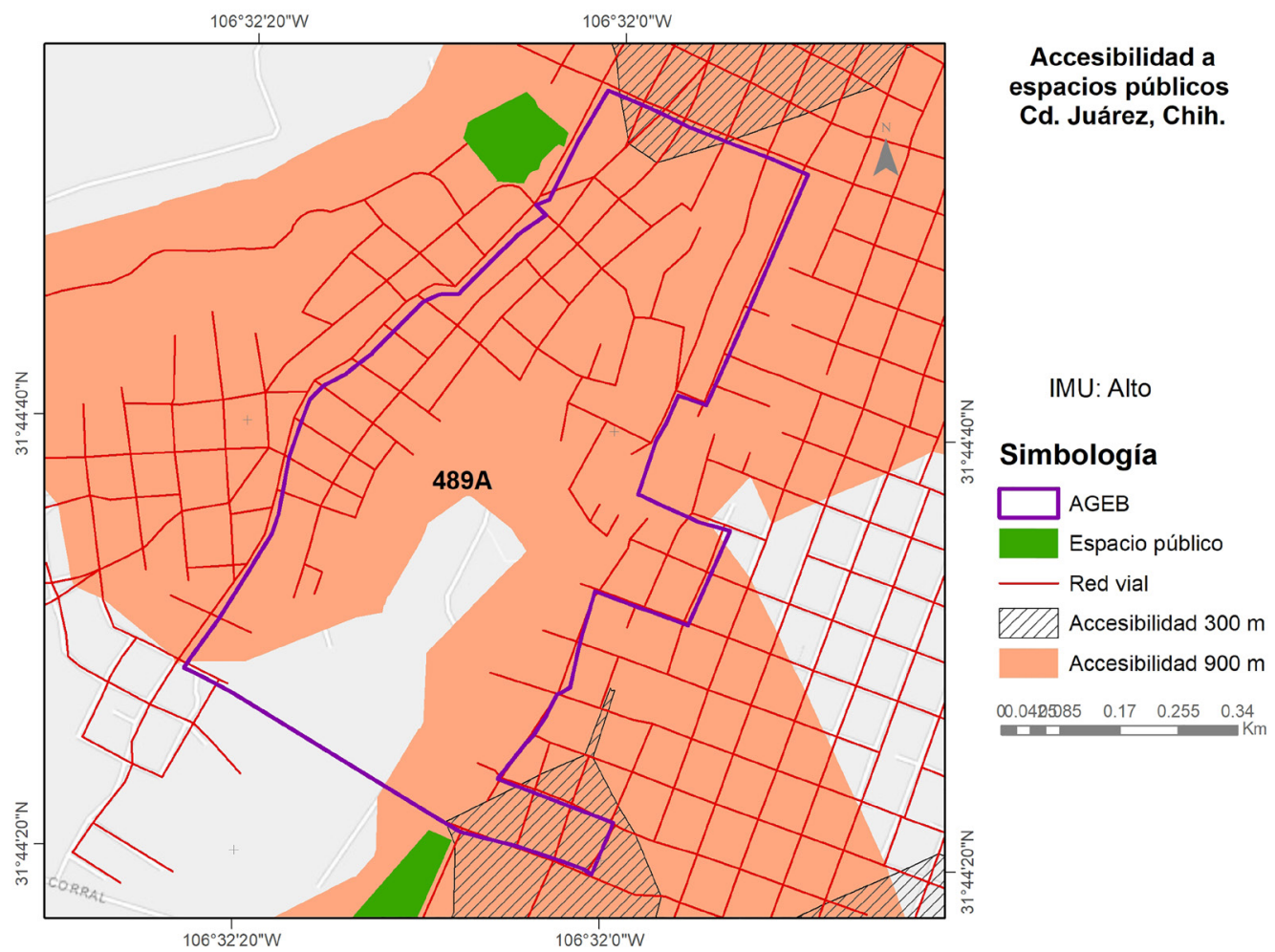

FIGURA 9. Accesibilidad a espacios públicos en zona de marginación alta: AGEB 489A FUENTE: elaboración propia.

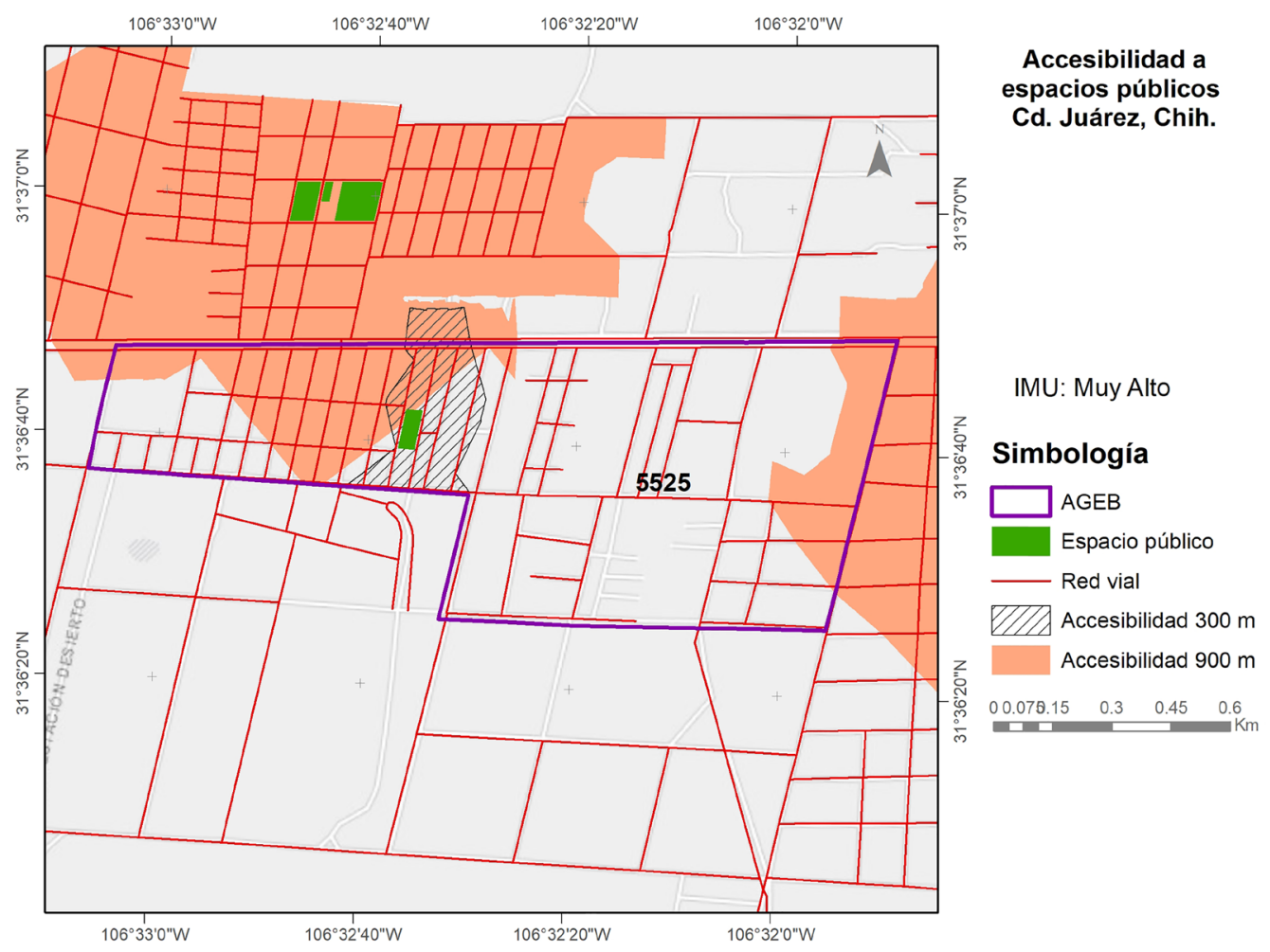

FIGURA 10. Accesibilidad a espacios públicos en zona de marginación muy alta: AGEB 5525 FUENTE: elaboración propia. 


\section{Conclusiones}

El análisis espacial de accesibilidad a los espacios públicos y la distribución territorial de la marginación, para las cinco muestras realizadas en Ciudad Juárez, muestra que no necesariamente existe una relación directa, ya que puede haber zonas con marginación media o alta y que tienen mayor cobertura de acceso a los espacios públicos que las zonas con marginación muy baja y baja. El único caso en donde se pudo constatar esa relación directa es en el AGEB 5525, donde la marginación muy alta coincide con la falta de acceso a estos lugares.

Realizar el análisis de accesibilidad a partir de Network Analyst permitió obtener mejores resultados que los que pueden generarse a partir de radios de influencia con la herramienta buffer, ya que se utiliza la red vial como elemento de acceso.

Sin embargo, aún quedan elementos por reforzar, por ejemplo, añadir las barreras y limitaciones que pueden existir en una red vial como las calles cerradas, ya que Ciudad Juárez tiene un gran número de fraccionamientos privados y calles donde se han instalado casetas de vigilancia que limitan el acceso a todos por igual, o bien agregar el factor de pendiente topográfica; ese tipo de elementos favorecerían un análisis más detallado y muy posiblemente reducirían las áreas de servicio que tienen los espacios públicos. Además, esta información se debe combinar con un análisis de las condiciones en las que se encuentran estos sitios, ya que de nada sirve poder acceder a uno de ellos caminando en 5 o 15 minutos si el lugar no tiene el equipamiento adecuado para poder desarrollar las actividades que suponen este tipo de espacios.

El caso de Ciudad Juárez, Chihuahua, en la frontera norte de México, es un ejemplo de las ciudades latinoamericanas en donde el número de espacios públicos muy pequeños proliferan, no obstante, son sitios que carecen de los equipamientos y la funcionalidad para dar cobertura a la población, además de que muchos de ellos no tienen mantenimiento constante por parte de las autoridades por el elevado costo económico que implica atender espacios públicos fragmentados, lo que empeora la situación. Tener un número elevado de espacios públicos no significa que en la ciudad se tenga cobertura amplia de accesibilidad y que esté distribuida equitativamente para todos los sectores de la población, como se demostró en el análisis aquí presentado.

De manera general, se cree que las zonas en contextos de marginación elevada son las que carecen de servicios y accesibilidad a espacios públicos, sin embargo, ciertamente hay zonas en donde no existe marginación, pero que también tienen baja accesibilidad a estos.

Para que las ciudades puedan hacer frente a los déficits y desigualdades que se van acumulando continuamente en distintos rubros, es necesario replantear el esquema tradicional de planeación urbana cuyo fundamento sigue siendo el modelo racional comprehensivo y es imprescindible integrar ahora, como eje transversal de la planeación, la justicia social y el derecho a la ciudad. Particularmente, en relación con el tema de equipamiento de los espacios públicos de calidad, estos pueden convertirse en nodos integradores de nuevas centralidades urbanas, con lo que ello implica como sistema organizado que incorpora diferentes usos de suelo y diferentes densidades tipo smart growth, lo que redundaría en beneficios sociales, económicos y ambientales.

A partir de dichas centralidades configuradas por un espacio público, se conformaría una red urbana con amplia accesibilidad que daría cobertura a todos los sectores socioeconómicos de la ciudad y el espacio público se constituiría en el detonador fundamental del cambio, de esa forma se podrían lograr mejoras significativas en territorios marginados y a la vez consolidar de una forma integral aquellas áreas que no presentan marginación. 


\section{Referencias}

Alvarado, C., Adame, S., \& Sánchez, R. M. (2017). Habitabilidad urbana en el espacio público, el caso del centro histórico de Toluca, Estado de México. Sociedad y Ambiente, 13, 129-169. https://www.redalyc.org/ pdf/4557/455752309007.pdf

Asensi, J. (2015). La regeneración urbana a partir de la vivienda colectiva. Espacios comunes como lugares de relación entre lo público y lo privado. On thew@terfront, 40(1), 23-35. https://www.raco.cat/index.php/ Waterfront/article/view/300157

Barbosa, O., Tratalos, J., Armsworth, P., Davies, R., Fuller, R., Johnson, P., \& Gaston, K. (2007). Who benefits from access to green space? A case study from Sheffield, UK. Landscape and Urban Planning, 83(2-3), 187-195. https://www.sciencedirect.com/science/ article/pii/S0169204607000965

Borja, J. (2011). Espacio público y derecho a la ciudad. Viento Sur, 116, 39-49. https://cdn.vientosur.info/vscompletos/vs 116_Borja_EspacioPublico.pdf

Campos, G. I., \& Brenna, J. E. (2015). Repensando el espacio público social como un bien común urbano. Argumentos, 28(77), 157-176. http://www. scielo.org. $\mathrm{mx} /$ scielo.php? script=sci_arttext\&pi$\mathrm{d}=$ S0187-57952015000100008

Caquimbo, S., Ceballos, O. L., \& López, C. (2017). Espacio público, periferia urbana y derecho a la ciudad. Intervención parque Carcolí, Ciudad Bolívar. Revista INVI, 32(89), 113-143. http://revistainvi.uchile.cl/index.php/INvi/article/view/1035

Cardona, B. M. (2008). Espacios de ciudad y estilos de vida. El espacio público y sus apropiaciones. Revista Educación Física y Deporte, 27(2), 39-47. https://revistas. udea.edu.co/index.php/educacionfisicaydeporte/article/view/2246

Ceballos, O. L. (2008). La cualificación de la periferia urbana y el espacio público. Una reflexión desde las políticas públicas de Bogotá. Territorios, 18(19), 207-227. https:// dialnet.unirioja.es/servlet/articulo? codigo $=3013008$

Consejo Nacional de Evaluación de la Política de Desarrollo Social (Coneval) (2021). ¿Quiénes somos? https:// www.coneval.org.mx/quienessomos/Paginas/Quienes-Somos.aspx

Consejo Nacional de Población (Conapo) (2010). Índices de marginación. http://www.conapo.gob.mx/en/coNAPO/Indices_de_Marginacion
Consejo Nacional de Población (Conapo) (2019). ¿Qué hacemos. https://www.gob.mx/conapo/que-hacemos

Cortés, F. (2006). Consideraciones sobre la marginación, la marginalidad, marginalidad económica y exclusión social. Papeles de Población, 12(47), 71-84. http:// www.scielo.org.mx/scielo.php?script=sci_arttext\&pi$\mathrm{d}=$ S1405-74252006000100004

Dávila, A., Corona, E. A., Pinedo, A., Jiménez, G., Pinedo, C., Rojas, R. I., \& Ranfla, A. (2016). Marginación y cambio de cobertura y uso del suelo de la zona metropolitana de Chihuahua. Investigación y Ciencia, 24(67), 38-45. https://www.redalyc.org/jatsRepo/674/67446178006/html/index.html

De la Torre, M. I. (2015). Espacio público y colectivo social. Nova Scientia, 7(14), 495-510. https://www.redalyc.org/pdf/2033/203338783026.pdf

Duhau, E. \& Giglia, Á. (2004). Conflictos por el espacio y orden urbano. Estudios Demográficos y Urbanos, 56, 257 288. https://www.redalyc.org/pdf/312/31205601.pdf

Figueroa, I. (2008). Conectividad y accesibilidad de los espacios abiertos urbanos de Santiago de Chile. [Tesis de maestría]. Pontífica Universidad Católica de Chile. https:// books.google.com.co/books/about/Conectividad_y_accesibilidad_de_los_espa.html?id=8bRuQwAACAAJ\&redir_esc $=\mathrm{y}$

Filipe, C. (2017). La intervención política en el espacio público: de la experiencia real a la ilusión deformada. Arquitectura y Urbanismo, 38(1), 36-47. https://www.redalyc.org/articulo.oa?id=376850994004

Fonseca, J. M. (2014). La importancia y la apropiación de los espacios públicos en las ciudades. Paakat: Revista de Tecnología y Sociedad, 4(7), 1-12. http://www.udgvirtual.udg.mx/paakat/index.php/paakat/article/ view/222/329

Franco, Á. M. \& Zabala, S. K. (2012). Los equipamientos urbanos como instrumentos para la construcción de ciudad y ciudadanía. DEARQ - Revista de Arquitectura / Fournal of Architecture, 11, 10-21. https://www.redalyc. org/pdf/3416/341630320003.pdf

García, G., Oliva, Y., \& Ortiz, R. (2012). Distribución espacial de la marginación urbana en la ciudad de Mérida, Yucatán, México. Investigaciones Geográficas (Mx), 77, 89-106. https://www.redalyc.org/articulo. oa?id=56923353008

Guzmán, A., Gómez, J. A., \& Muñoz, C. D. (2015). Estudio sobre la configuración y función del espacio público en zonas de marginación urbana. Caso de estudio "La 
Joya” en la ciudad de León, Guanajuato, México. Revista Legado de Arquitectura y Diseño, 17, 139-161. https:/ / www.redalyc.org/jatsRepo/4779/477947305010/ $\mathrm{html} /$ index.html

Handley, J., Pauleit, S., Slinn, P., Lindley, S., Baker, M., Barber, A., \& Jones, C. (2003). Providing accesible natural greenspace in towns and cities. A practical guide to assessing the resource and implementing local standards for provision. English Nature. http://publications.naturalengland. org.uk/file/78003

Harrison, C., Burgess, J., Millward, A., \& Dawe, G. (1995). Accesible natural greenspace in towns and cities: A review of appropiate size and distance criteria. English Nature, 8, 1-42. http://publications.naturalengland. org.uk/publication/62097

Hernandez, M. (2015). Public policies and programmes for public space improvement in Mexico in the 21st century: The case of Xalapa. Global Urban Research Centre Working Paper $\mathrm{n}^{\circ}$ 10. The University of Manchester. https:// hummedia.manchester.ac.uk/institutes/mui/gurg/ working_papers/GURC_wp10.pdf

Herrera, D. (2017). Equipamiento urbano y participación comunitaria como alternativas para la reducción de la inseguridad y delincuencia en Ciudad Juárez, Chihuahua (2016-2017). [Tesis de maestría]. Universidad Autónoma de Ciudad Juárez.

Hidalgo, A. H. (2017). El espacio público como vinculante territorial. Teoría y aplicación en una colonia marginal de México. Revista de Estudios Andaluces, 34(1), 226254. https://doi.org/10.12795/rea.2017.i34.08

Instituto Municipal de Investigación y Planeación (IMIP) (2016). Plan de Desarrollo Urbano Sostenible Ciudad Juárez 2016. https://www.imip.org.mx/imip/files/ sites/pdus2016/

Instituto Municipal de Investigación y Planeación (IMIP) (2017). Base de datos sobre espacios públicos. [Archivo digital].

Instituto Nacional de Estadística y Geografía (INEGI) (2010). Censo de Población y Vivienda. https://www.inegi. org.mx/programas/ccpv/2010/

López, J. G. (2012). El derecho al espacio público. Provincia, 27, 105-136. https://www.redalyc.org/ pdf/555/55526545002.pdf

Magrinyá, F. \& Mayorga, M. Y. (2008). Diseñar la ciudad para el deporte en los espacios públicos. Apunts. Educación fisica y deportes, 1(91), 102-113. https:// www.raco.cat/index.php/ApuntsEFD/article/viewFile/300084/389553
Mier y Terán, A., Vázquez, I., \& Ziccardi, A. (2012). Pobreza urbana, segregación residencial y mejoramiento del espacio público en la Ciudad de México. $S_{0}$ ciologías, 14(30), 118-155. https://doi.org/10.1590/ S1517-45222012000200005

Murillo Torrecilla, F. \& Hernández Castilla, R. (2011). Hacia un concepto de Justicia Social. REICE, Revista Iberoamericana sobre Calidad, Eficacia y Cambio en Educación, 9(4), 7-23. https://www.redalyc.org/ pdf/551/55122156002.pdf

Ocampo, D. R. (2013). Eficiencia del equipamiento urbano y su incidencia en la formulación de proyectos productivos en la ciudad. Revista URBANO, 16(27), 48-57. https://www.redalyc.org/pdf/198/19836964008. pdf

Páramo, P., Burbano, A., \& Fernández, D. (2016). Estructura de indicadores de habitabilidad del espacio público en ciudades latinoamericanas. Revista de Arquitectura (Bogotá), 18(2), 6-26. https://doi.org/10.14718/RevArq.2016.18.2.2

Pérez Pulido, L. \& Romo Aguilar, M. (2019). Modelo analítico de justicia socio-territorial: implicaciones de la expansión urbana en el desarrollo social. Economía, Sociedad y Territorio, 19(61), 479-506. https://doi. org/10.22136/est20191365

Puig, N., Villanova, A., Camino, X., Maza, G., Pasarello, M., Juan, D., \& Tarragó, R. (2006). Los espacios públicos urbanos y el deporte como generadores de redes sociales. El caso de la ciudad de Barcelona. Apunts. Educación fisica y deportes, 2(84), 76-87. https:// www.raco.cat/index.php/ApuntsEFD/article/download/300836/390281

Restrepo, S. (2016). Espacio público: emergencia, conflictos y contradicciones. Caso ciudad de Medellín. Revista de la Facultad de Derecho y Ciencias Políticas - UPB, 46(125), 291-328. http://www.scielo.org.co/scielo. php?pid $=$ S0120-38862016000200004\&script $=$ sci_ abstract\&tlng $=\mathrm{es}$

Romo, M. (2007). Áreas verdes y justicia social en Ciudad Juárez, Chihuahua. Crisol, 1(3), 9-24. http://www3. uacj.mx/IADA/Documents/REVISTAS/CRISOL/revistas $/$ Crisol\%205.pdf

Simian, M. P. (2014). Estudio de accesibilidad de espacios público-privado en la ciudad de Temuco-Chile. Método de valoración de accesibilidad. Revista de la Universidad Industrial de Santander. Salud, 46(3), 267-276. https: / / www.redalyc.org/articulo.oa?id=343838645007 
Stuart, P. (2011). La práctica deportiva y su relación directa con el uso de los escenarios públicos y privados del barrio Castilla de la ciudad de Medellín. [Tesis de especialización]. Universidad de Antioquia, Medellín, Colombia. http:// viref.udea.edu.co/contenido/pdf/270-lapractica.pdf
Urbina, Y. (2014). Espacio público urbano como catalizador de actividad física y bienestar psicológico. Wimb Lu, Revista Electrónica de Estudiantes de Psicología de la Universidad de Costa Rica, 9(1), 67-81. https://revistas.ucr. ac.cr/index.php/wimblu/article/view/13551 